\title{
Hemoglobin Vesicles prolong the time to circulatory collapse in rats during apnea
}

\author{
Yusuke Naito $^{1^{*}} \mathbb{D}$, Hiromi Sakai ${ }^{2}$, Satoki Inoue ${ }^{1}$ and Masahiko Kawaguchi ${ }^{1}$
}

\begin{abstract}
Background: Hemoglobin vesicles ( $\mathrm{HbV}$ ) are hemoglobin-based oxygen carriers manufactured by liposome encapsulation of hemoglobin molecules. We hypothesised that the infusion of oxygenated $\mathrm{HbV}$ could prolong the time to circulatory collapse during apnea in rats.

Methods: Twenty-four Sprague-Dawley rats were randomly divided into four groups (Air, Oxy, NS and HbV). The rats were anaesthetized with isoflurane and the trachea was intubated using 14-gauge intravenous catheters. Rats in the Air group were mechanically ventilated with 1.5\% isoflurane in room air, and those in other groups received 1.5\% isoflurane in 100\% oxygen. Mechanical ventilation was withdrawn $1 \mathrm{~min}$ after the administration of rocuronium bromide to induce apnea. After $30 \mathrm{~s}, 6 \mathrm{~mL}$ saline and $\mathrm{HbV}$ boluses were infused at a rate of $0.1 \mathrm{~mL} / \mathrm{s}$ in the NS and $\mathrm{HbV}$ groups, respectively. Circulatory collapse was defined as a pulse pressure $<20 \mathrm{mmHg}$ and the time to reach this point $\left(\mathrm{PP}_{20}\right)$ was compared between the groups. The results were analysed via a one-way analysis of variance and post-hoc Holm-Sidak test.

Results: $\mathrm{PP}_{20}$ times were $30.4 \pm 4.2 \mathrm{~s}, 67.5 \pm 9.7 \mathrm{~s}, 95 \pm 17.3 \mathrm{~s}$ and $135 \pm 38.2 \mathrm{~s}$ for the Air (ventilated in room air with no fluid bolus), Oxy (ventilated with 100\% oxygen with no fluid bolus), NS (ventilated with $100 \%$ oxygen with a normal saline bolus), and HbV (ventilated in 100\% oxygen with an HbV bolus) groups, respectively, and differed significantly between the four groups $(P=0.0001)$. The $\mathrm{PP}_{20}$ times in the HbV group were significantly greater than in the Air $(P=0.0001)$, Oxy $(P=0.007)$ and NS $(P=0.04)$ groups.
\end{abstract}

Conclusion: Infusion of oxygenated HbV prolongs the time to circulatory collapse during apnea in rats.

Keywords: Hemoglobin Vesicles, Artificial red blood cells, Apnea, Hypoxia

\section{Background}

The situation 'cannot ventilate, cannot intubate (CVCI)' during the induction of anaesthesia is one of the most serious complications anaesthesiologists can encounter. In some cases, supraglottic airway devices may help to maintain oxygenation, but otherwise, the reinitiation of spontaneous ventilation by waking the patient, or the initiation of emergency intubation pathways, should be considered [1]. Even after the introduction of fast-acting drugs and Sugammadex, the time required for the reestablishment of spontaneous breathing is often longer than expected [2]. Emergency intubation pathways commonly involve invasive airway access that require at least a few minutes of preparation. These techniques are also

\footnotetext{
* Correspondence: schneider.yusuke@gmail.com

${ }^{1}$ Department of Anesthesiology, Nara Medical University, 840 Shijo-cho,

Kashihara, Nara 634-8522, Japan

Full list of author information is available at the end of the article
}

highly invasive, and each carries a substantial risk of technical complications [3].

Hemoglobin vesicles ( $\mathrm{HbV}$ ) are a type of cellular $\mathrm{Hb}$ based oxygen carrier (HBOC) manufactured by the encapsulation of a purified, concentrated $\mathrm{Hb}$ solution using liposomes [4]. Moreover, $\mathrm{HbV}$ was developed as an alternative to red blood cell (RBC) transfusion and has exhibited efficacy as components of the resuscitative fluid used to treat haemorrhagic shock in emergency situations using animal models $[5,6]$. The absence of a blood type antigen and infectious viruses, the small particle size required for penetration via constricted vessels through which red blood cells cannot penetrate, and the stability for long-term storage at room temperature are also important advantages of $\mathrm{HbV}$ [7]. In practice, $\mathrm{HbV}$ is stored in a deoxygenated state, but is rapidly oxygenated and administered within extremely short time periods. 
Therefore, we hypothesised that the infusion of oxygenated $\mathrm{HbV}$ could maintain oxygenation in critical situations (e.g. CVCI) after the induction of anaesthesia. Accordingly, we tested whether the administration of $\mathrm{HbV}$ could prolong the time to circulatory collapse during apnea in a rat model.

\section{Methods}

All experiments were conducted using 24 male SpragueDawley rats (300-330 g, 10 weeks old). All animals were purchased from SLC Inc., Shizuoka, Japan. The animals were housed on a bed of cellulose paper in a ventilated, temperature controlled, specific-pathogen-free environment with a 12-h light-dark cycle. The animals were provided with access to food and water ad libitum. All experimental protocols were reviewed by the Committee on the Ethics of Animal Experiments at our University and were conducted in accordance with the Guidelines for Animal Experiments issued by the Nara Medical University and with law no. 105 (Act on Welfare and Management of Animals) issued by the Japanese government. The ethical guidelines conformed to the guiding principles issued by the National Academy of Science.

\section{Pilot study to define circulatory collapse}

To perform a thorough investigation, we first sought to define the criteria for circulatory collapse. There are previous reports of apnea in rat models; however, there is no consensus on the definition of circulatory collapse in these reports $[8,9]$. Moreover, a number of previous studies have used the mean arterial pressure or systolic blood pressure to define circulatory collapse $[10,11]$; however, these criteria were not used in the present study as volume infusions lead to a $30 \%$ increase in the total blood volume of the rats, likely resulting in an increased mean arterial and systolic blood pressure. Instead, we used the pulse pressure to define circulatory collapse in our study. We assessed a range of pulse pressures $(5,10,15,20$ and $25 \mathrm{mmHg})$ as surrogates of circulatory collapse. The same equipment and drugs described in the experimental methodology were used in this pilot study. In brief, five rats were orally intubated after the induction of anaesthesia via the inhalation of $5 \%$ isoflurane in $100 \%$ oxygen. The trachea of the rats was then intubated using 14-gauge intravenous catheters. Mechanical ventilation was initiated with $1.5 \%$ isoflurane in room air at $1 \mathrm{~L} / \mathrm{min}$ and oxygen at $1 \mathrm{~L} / \mathrm{min}$ to maintain an $\mathrm{FIO}_{2}$ of 0.6. Adequate anaesthesia was confirmed by the absence of the pedal withdrawal reflex in response to tail pinching. Polyethylene catheters were introduced into the tail arteries to monitor the arterial blood pressure. Polyethylene catheters were also introduced into the external right jugular vein for the purpose of drug administration. Apnea was induced by the administration of $1 \mathrm{mg}$ of rocuronium bromide to inhibit spontaneous breathing followed by extubation. The apnea times for the pulse pressures of $5,10,15,20$ and $25 \mathrm{mmHg}$ were recorded. The mean arterial and systolic blood pressures were also recorded for a comparison with the pulse pressure. Coefficients of variation ( $\mathrm{CV}$, standard deviation divided by the mean value) were calculated. The pulse pressure with the lowest $\mathrm{CV}$ was defined as a circulatory collapse.

\section{Preparation of $\mathrm{HbV}$}

$\mathrm{HbV}$ was prepared under sterile conditions, according to previously reported methods with only slight modifications [12]. Hemogloin $(\mathrm{Hb})$ was purified from outdated donated human blood provided by the Japanese Red Cross Society (Tokyo, Japan). First, Hb was stabilised using carbonylation $(\mathrm{HbCO})$ and pasteurized $\left(60{ }^{\circ} \mathrm{C}\right.$ for $12 \mathrm{~h}$ ) to inactivate any viruses. All unstable enzymes are also eliminated by this procedure. The obtained $\mathrm{Hb}$ solution was concentrated by ultrafiltration to $42 \mathrm{~g} / \mathrm{dL}$. Subsequently, pyridoxal 5'-phosphate (PLP; Sigma Chemical Co., St. Louis, $\mathrm{MO}$ ) was added to the $\mathrm{HbCO}$ solution as an allosteric effector at a molar ratio of PLP/ $\mathrm{Hb}$ tetramer $=1$. The $\mathrm{Hb}$ solution with PLP was then mixed with lipids and encapsulated in vesicles. The lipid bilayer comprised 1,2-dipalmitoyl-sn-glycero-3-phosphatidylcholine, cholesterol, 1,5-O-dihexadecyl- $\mathrm{N}$-succinyl-L-glutamate (Nippon Fine Chemical Co. Ltd., Osaka, Japan) and 1,2-distearoyl-sn-glycerol-3-phosphatidylethanolamine-N-PEG5000 (NOF Corp., Tokyo, Japan) at a molar ratio of 5:4:0.9:0.03, respectively. The encapsulated $\mathrm{HbCO}$ was converted to $\mathrm{HbO}_{2}$ by exposing the liquid membranes of $\mathrm{HbV}$ to visible light under an $\mathrm{O}_{2}$ atmosphere. $\mathrm{HbV}$ was dialysed in normal saline to adjust the $\mathrm{Hb}$ concentration to $10 \mathrm{~g} / \mathrm{dL}$. Finally, the preparation was completely deoxygenated for long-term storage. The physiochemical parameters of $\mathrm{HbV}$ are as follows; $\mathrm{P}_{50}$, 17 - $23 \mathrm{mmHg}$; $251 \pm 81 \mathrm{~nm}$ particle diameter; and less than $10 \%$ metHb content. Immediately before administration, deoxygenated $\mathrm{HbV}$ was drawn into a $10-\mathrm{mL}$ syringe (Terumo Co., Tokyo, Japan) and rapidly oxygenated by mixing with air.

\section{Main experimental design}

A schematic of the experimental design is shown in Fig. 1. Before the experiment, the rats were randomised into four groups (Air, Oxy, NS and HbV groups) and anaesthetised via the inhalation of 5\% isoflurane (Mylan Inc. PA, USA) in $100 \%$ oxygen inside a plastic chamber. Once unconscious, tracheal intubation was performed using a 14-gauge intravenous catheter via direct laryngoscopy. The rats in the Air group were mechanically ventilated with $1.5 \%$ isoflurane in room air, while the rats in the other groups were ventilated with 1.5\% 


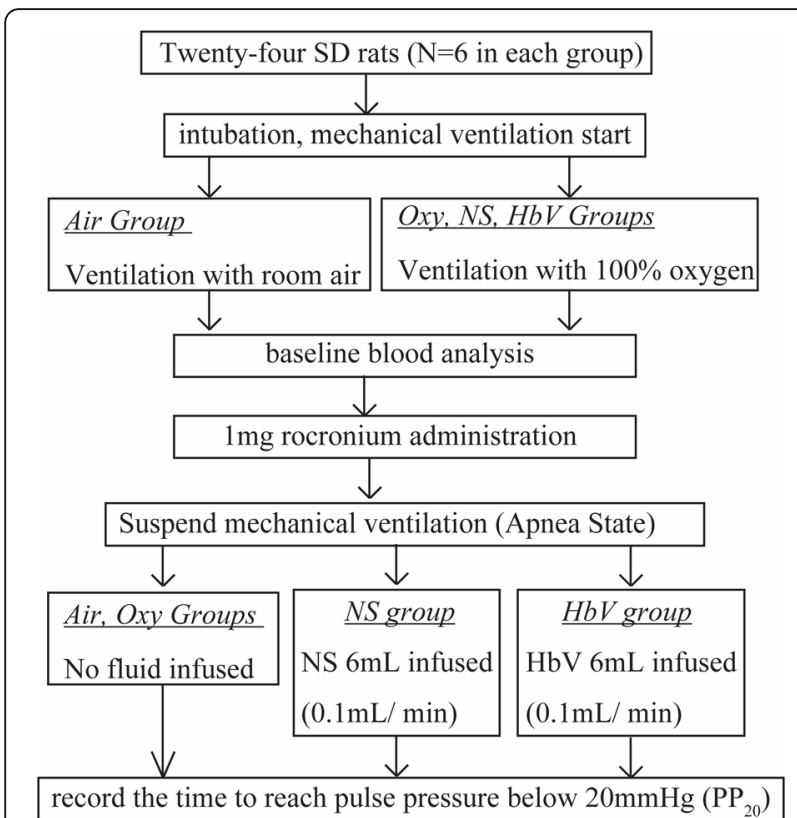

Fig. 1 Outline of the experiment protocol. After the administration of rocuronium bromide, the mechanical ventilation was withdrawn to establish apnea. The apnea time to a pulse pressure less than $20 \mathrm{mmHg}$ was compared between the groups

isoflurane in 100\% oxygen. All mechanical ventilation was performed using a small animal ventilator (Harvard Model 683, HARVARD APPARATUS, MA, USA). The respiratory rate was set to maintain $\mathrm{pCO}_{2}$ at $35-45 \mathrm{mmHg}$. The typical ventilator rates ranged between 55 and 65 breaths/ min with a tidal volume of $8 \mathrm{~mL} / \mathrm{kg}$. The adequate anaesthesia depth was confirmed as described in the pilot study. Polyethylene catheters (SP45) filled with heparinised normal saline were inserted into the tail arteries to measure the arterial pressure. Polyethylene catheters filled with heparinised normal saline (SP55) were introduced via the right jugular vein into the right atrium for the purpose of drug infusion. Both types of polyethylene catheters were purchased from Natsume Seisakusho Co. Ltd. Tokyo, Japan. The blood pressure and pulse rate were monitored using a continuous monitoring system (PROPAQ 204 EL; Welch Allyn. NY, USA). The rectal temperature was maintained between $36.0{ }^{\circ} \mathrm{C}$ and $37.5{ }^{\circ} \mathrm{C}$ with the aid of thermal lighting during experiments. The baseline ( $3 \mathrm{~min}$ before insult) arterial blood analysis was performed (GEM Premiere 3000; Instrumental Laboratory, MA, USA) following the administration of 300 units of heparin to ensure that all values were within the normal range.

\section{Induction of apnea}

A total dose of $1 \mathrm{mg}$ rocuronium bromide (MSD. Inc., Tokyo, Japan) was administered while the animals were still under anaesthesia. The tracheal tubes were then removed and mechanical ventilation was withdrawn to establish apnea. The animals were visually observed to ensure that spontaneous breathing did not recover during the experiments. In addition, the rats in the Air and Oxy groups did not receive a fluid infusion during apnea. After a 30-s interval following ventilation withdrawal, the rats in $\mathrm{NS}$ and $\mathrm{HbV}$ groups received infusions of $6 \mathrm{~mL}$ normal saline or $\mathrm{HbV}$, respectively, at a rate of $0.1 \mathrm{~mL} / \mathrm{s}$. The blood pressure and pulse rate were continuously recorded following the withdrawal of mechanical ventilation using a monitor display and video camera (iPad mini; Apple Inc., CA, USA). We defined a circulatory collapse as a pulse pressure less than $20 \mathrm{mmHg}$ according to our preliminary study. The time to a pulse pressure less than $20 \mathrm{mmHg}$ $\left(\mathrm{PP}_{20}\right)$ was compared between the groups as the primary study outcome. Video recording was continued until the pulse pressure fell below $10 \mathrm{mmHg}$ or until $180 \mathrm{~s}$ had expired. After the experiment, all rats were euthanised by an intravenous administration of $4 \mathrm{mEq}$ potassium chloride.

\section{Randomisation and blinding of the experiment}

The animals were randomly assigned to four groups before the induction of apnea. Randomisation was performed using a computer-generated randomisation table. The investigators who performed the experiments were not blinded since it was easy to distinguish which fluid was administered. The video recordings were investigated by a researcher who was blinded to the animal groups.

\section{Statistical analyses}

Fully saturated Hemoglobin vesicles contain approximately $0.8 \mathrm{~mL}$ oxygen in a $6-\mathrm{mL}$ solution according to the formula: Oxygen Content $=1.34 *[\mathrm{Hb}] *\left[\mathrm{SaO}_{2}\right]=1.34$ * $10^{*} 1.00$. The oxygen consumption of adult rats is reported to be $0.68 \mathrm{~mL} / \mathrm{g} / \mathrm{h}(0.056 \mathrm{~mL} / \mathrm{s})$ [13]. We considered half of the time derived from the calculation $(8 \mathrm{~s})$ to be clinically significant (between group variance $=64$ ). The within group variance calculated from the pilot study was 55 .

A power analysis demonstrated that a group size of $n=5$ was necessary to detect a difference in the mean $\mathrm{PP}_{20}$ values between the groups assuming a statistical power of 0.8 at a significance level of 0.05 . We included six rats in each group to mitigate any loss due to accidental death or circulatory collapse during the study.

Means \pm standard deviation are reported for all measurements unless otherwise specified. All of the data sets were analysed using Statflex software (Artech Inc., Tokyo, Japan). To reduce multiple comparisons, differences in the haemodynamic changes during apnea were compared at three time points (30, 90 and $150 \mathrm{~s}$ ) by a repeated measure ANOVA followed by the Holm-Sidak test. Thirty seconds following the establishment of apnea was selected as the first time point as the fluid infusions were initiated at this time. As the fluids were infused for a duration of $60 \mathrm{~s}$, the 
next time point used was $90 \mathrm{~s}$, and a further time point at $150 \mathrm{~s}$ was chosen to maintain consistent intervals. Differences in the $\mathrm{PP}_{20}$ between each of the groups were analysed by a one-way ANOVA followed by the Holm-Sidak test. Since $\mathrm{PP}_{20}$ is a time-to-event variable, we also plotted it as a Kaplan-Meier curve with a log-rank analysis. The $P$ values correspond to two-tailed tests with statistical significance set at $P<0.05$.

\section{Results}

\section{Pilot study to define circulatory collapse}

The results of the 'Pilot study to define circulatory collapse' are presented in Table 1 . We found that the apnoea time to a pulse pressure lower than $20 \mathrm{mmHg}$ had the lowest CV value of 0.18 . Therefore, we defined a pulse pressure lower than $20 \mathrm{mmHg}$ as a surrogate outcome for the circulatory collapse in our main study.

\section{Baseline measurements}

The initial body weight, preparation time and blood loss until apnea demonstrated small standard deviations within each group and did not differ significantly between groups. One rat in the Air group was excluded from the study due to a technical error. Therefore, all the results shown below are derived from 23 rats $(n=5$ for the Air group; $n=6$ for all the other groups).

The systolic blood pressure, mean arterial pressure, pulse pressure and pulse rate measurements at baseline for each group are shown in Table 2. The rats in the Air group exhibited a lower systolic blood pressure, mean arterial pressure and pulse pressure at baseline compared to the other groups. No significant difference in

Table 1 Study results of the apnea times to haemodynamic values

\begin{tabular}{|c|c|c|c|c|}
\hline \multirow{2}{*}{\multicolumn{2}{|c|}{$\begin{array}{l}\text { Blood pressure } \\
(\mathrm{mmHg})\end{array}$}} & \multicolumn{3}{|c|}{ Apnea time (s) } \\
\hline & & \multirow{2}{*}{$\frac{\text { Mean }}{100.6}$} & \multirow{2}{*}{$\frac{\text { S.D. }}{40.1}$} & \multirow{2}{*}{$\frac{C V}{0.39}$} \\
\hline SBP & 30 & & & \\
\hline & 25 & 113.8 & 42.1 & 0.36 \\
\hline & 20 & 123.8 & 38.2 & 0.30 \\
\hline \multirow[t]{3}{*}{ MAP } & 20 & 122.6 & 39.2 & 0.31 \\
\hline & 15 & 143.8 & 33.9 & 0.23 \\
\hline & 10 & 192.3 & 68.6 & 0.35 \\
\hline \multirow[t]{5}{*}{ PP } & 25 & 26.6 & 7.9 & 0.29 \\
\hline & 20 & 39.4 & 7.2 & 0.18 \\
\hline & 15 & 46 & 9.4 & 0.20 \\
\hline & 10 & 68.8 & 37.9 & 0.55 \\
\hline & 5 & 78.8 & 41.2 & 0.52 \\
\hline
\end{tabular}

Data are presented in seconds. A pulse pressure below $20 \mathrm{mmHg}$ had the lowest CV (Coefficients of variation) and was used to define the circulatory collapse experimentally. All rats $(n=5)$ were mechanically ventilated with room air at $1 \mathrm{~L} / \mathrm{min}$ and oxygen at $1 \mathrm{~L} / \mathrm{min}$ to maintain $\mathrm{FIO}_{2}=0.6$ $S B P$ systolic blood pressure; MAP mean arterial pressure; $P P$ pulse pressure
Table 2 Haemodynamic variables at baseline

\begin{tabular}{lllll}
\hline & Air & Oxy & NS & HbV \\
\hline SBP $(\mathrm{mmHg})$ & $67.4(8.1)$ & $99.8(20.5)^{\mathrm{a}}$ & $103.1(13.7)^{\mathrm{a}}$ & $113.1(13.1)^{\mathrm{a}}$ \\
MAP $(\mathrm{mmHg})$ & $54.8(5.8)$ & $79.3(15.9)^{\mathrm{a}}$ & $84.5(11.3)^{\mathrm{a}}$ & $92.3(11.7)^{\mathrm{a}}$ \\
PP (mmHg) & $21.8(5.1)$ & $28.7(4.5)^{\mathrm{a}}$ & $28.1(5.7)^{\mathrm{a}}$ & $31.8(4.1)^{\mathrm{a}}$ \\
PR (beats $\left.\mathrm{min}^{-1}\right)$ & $421.6(14.2)$ & $450.5(41.3)$ & $410.8(42.2)$ & $425.0(58.9)$ \\
\hline
\end{tabular}

There was no difference in haemodynamic variables between Oxy, NS and $\mathrm{HbV}$ groups at baseline. ${ }^{\mathrm{a}}$ statistically significant difference from the Air group analysed by one-way ANOVA followed by a Holm-Sidak test $(P<0.01)$ $S B P$ systolic blood pressure; MAP mean arterial pressure; $P P$ pulse pressure; $P R$ pulse rate

the systolic blood pressure, mean arterial pressure, or pulse pressure was observed between the NS, Oxy and $\mathrm{HbV}$ groups. The pulse rate at baseline was similar between all groups.

The baseline blood analysis was performed prior to the induction of apnea. Table 3 summarises the baseline blood analyses. Rats in the Air group had significantly lower $\mathrm{pO}_{2}$ as they were ventilated with room air while the other groups were ventilated with $100 \%$ oxygen. All of the other variables were within the normal range with no differences were observed between groups.

\section{Haemodynamic changes during apnea}

The systolic blood pressure, mean arterial pressure and pulse pressure measurements at $60 \mathrm{~s}$ intervals for each group are shown in Fig. 2. The systolic blood pressure, mean arterial pressure and pulse pressure was significantly lower in the Air group at $30 \mathrm{~s}$ compared to the other groups, while no differences were observed between the Oxy, NS and HbV groups. At $90 \mathrm{~s}$, the systolic blood pressure, mean arterial pressure and pulse pressure were significantly higher in the $\mathrm{HbV}$ group compared to all other groups. At $150 \mathrm{~s}$, the pulse pressure in the $\mathrm{HbV}$

Table 3 Baseline arterial blood analysis

\begin{tabular}{lllll}
\hline & Air & Oxy & $\mathrm{NS}$ & $\mathrm{HbV}$ \\
\hline $\mathrm{pH}$ & $7.44(0.04)$ & $7.46(0.03)$ & $7.40(0.09)$ & $7.42(0.08)$ \\
$\mathrm{pO}_{2}(\mathrm{mmHg})$ & $73.4(18.0)$ & $399.1(37.5)^{\mathrm{a}}$ & $466.3(53.9)^{\mathrm{a}}$ & $433(86.8)^{\mathrm{a}}$ \\
$\mathrm{pCO}_{2}(\mathrm{mmHg})$ & $37.4(2.2)$ & $33.3(3.4)$ & $42.7(17.1)$ & $40.5(7.3)$ \\
$\mathrm{Hct}(\%)$ & $40(2.9)$ & $39.5(3.7)$ & $38(3.7)$ & $37.8(1.5)$ \\
$\mathrm{Hb}(\mathrm{g} / \mathrm{dL})$ & $12.4(0.9)$ & $12.5(1.3)$ & $11.8(1.2)$ & $11.8(0.4)$ \\
$\mathrm{Na}(\mathrm{mmol} / \mathrm{L})$ & $135.4(3.4)$ & $134.0(4.0)$ & $134.3(4.3)$ & $133.2(7.0)$ \\
$\mathrm{K}(\mathrm{mmol} / \mathrm{L})$ & $4.8(0.5)$ & $4.2(0.5)$ & $4.3(0.8)$ & $4.2(0.5)$ \\
$\mathrm{Ca}(\mathrm{mmol} / \mathrm{L})$ & $1.2(0.06)$ & $1.2(0.10)$ & $1.2(0.16)$ & $1.2(0.07)$ \\
$\mathrm{BE}(\mathrm{mmol} / \mathrm{L})$ & $1.62(2.1)$ & $-0.18(1.7)$ & $0.25(2.9)$ & $1.25(2.4)$ \\
\hline $\begin{array}{l}\mathrm{Hct} \text { haematocrit; } \\
\text { excess (mmol/L) }\end{array}$
\end{tabular}




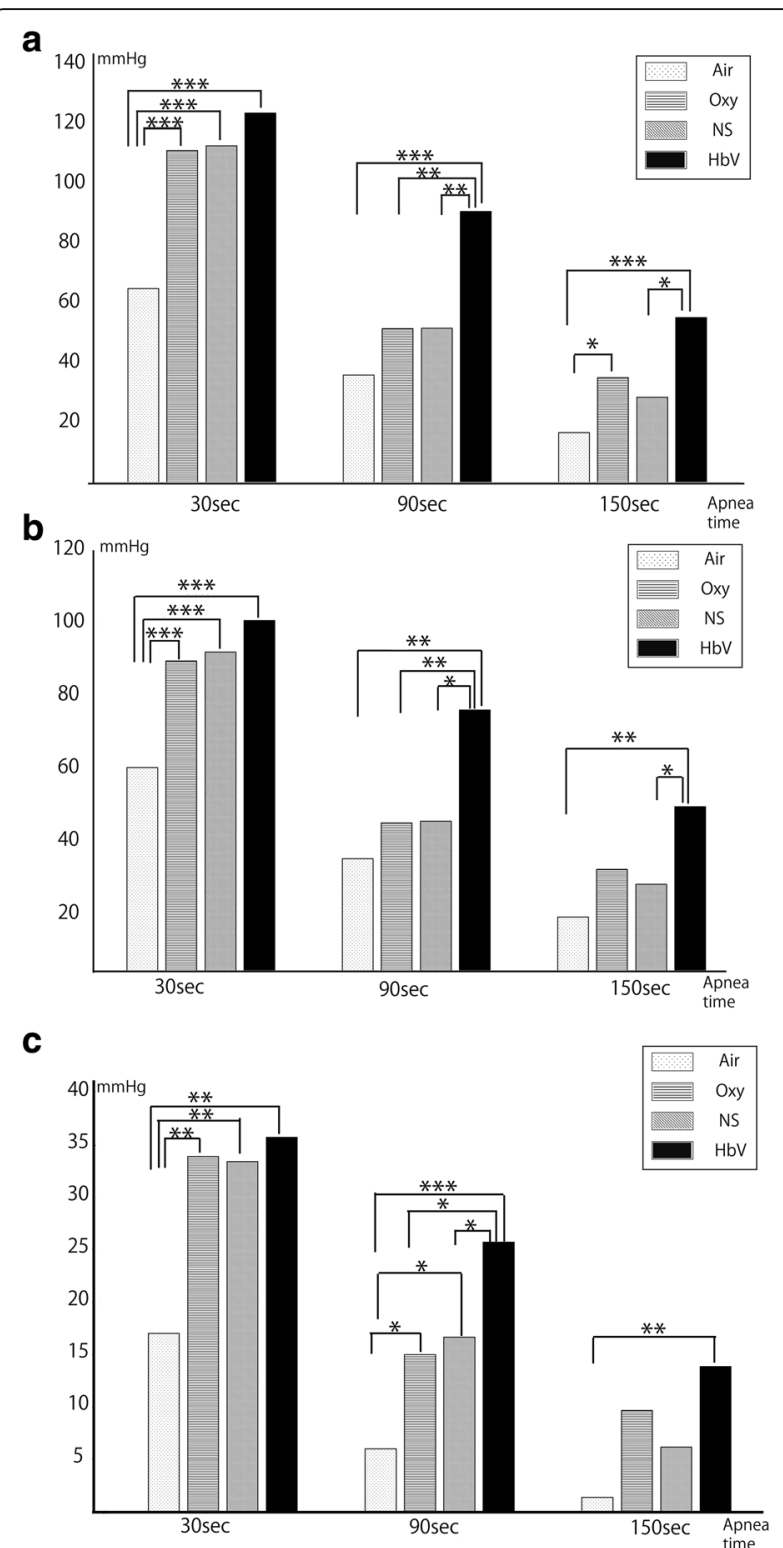

Fig. 2 Haemodynamic changes after the withdrawal of mechanical ventilation. Systolic blood pressure (a), mean arterial pressure (b) and pulse pressure (c) for each group are shown. The rats in the Air group were ventilated with room air while the other groups were ventilated with 100\% oxygen. The NS group were infused with $6 \mathrm{~mL}$ normal saline and the HbV group was infused with $6 \mathrm{~mL} \mathrm{HbV}$. The arrows indicate periods of fluid infusion. The differences between the groups were analysed by a one-way repeated measure ANOVA followed by a Holm-Sidak test. SBP, systolic blood pressure; MAP, mean arterial pressure; $P P$, pulse pressure. Symbols represent significant differences. *: $P<0.05$; ${ }^{* *} P<0.01$; ${ }^{* *} P<0.001$

group was higher compared to the Air group, while there were no significant differences between the Oxy and NS groups. However, the systolic blood pressure and mean arterial pressure in the $\mathrm{HbV}$ group were consistently significantly higher than the Oxy and NS groups.
Apnea time to a pulse pressure less than $20 \mathrm{mmHg}\left(\mathrm{PP}_{20}\right)$ The apnea time to a pulse pressure less than $20 \mathrm{mmHg}$ $\left(\mathrm{PP}_{20}\right)$ was compared between the four groups as the primary outcome of this study. The mean $\mathrm{PP}_{20}$ values \pm standard deviation were $30.4 \pm 4.2$ s, $67.5 \pm 9.7$ s, $95 \pm$ $17.3 \mathrm{~s}$ and $135 \pm 38.2 \mathrm{~s}$ for the Air, Oxy, NS and HbV groups, respectively. The mean $\mathrm{PP}_{20}$ values for all groups significantly differed from every other group by a oneway ANOVA followed by Holm-Sidak test (Air vs. Oxy $P=0.0001$; Air vs. NS $P=0.0001$, Air vs. $\mathrm{HbV} P=0.002$, Oxy vs. NS $P=0.002$, Oxy vs. HbV $P=0.007$ and NS vs. HbV $P=0.04)$. The Kaplan-Meier curves for the apnea time to a pulse pressure less than $20 \mathrm{mmHg}$ are plotted in Fig. 3. A long rank analysis revealed statistical differences between the four groups. (Air vs. HbV $P=0.004$; Oxy vs. $\mathrm{HbV}, P=0.003$; $\mathrm{NS}$ vs. $\mathrm{HbV}, P=0.045)$. There were also similar trends regarding the time to reach pulse pressures below 15 [see Additional file 1] and $10 \mathrm{mmHg}$ [see Additional file 2] between the groups.

\section{Discussion}

To the best of our knowledge, this is the first report to demonstrate the effect of hemoglobin based oxygen carrier (HBOC) therapy during apnea. We found that the administration of oxygenated $\mathrm{HbV}$ more than doubled the apnea time to circulatory collapse when compared to the Oxy group.

In 1949, Amberson reported the first case series of clinical experiences using an Hb-saline solution [14]. Although it was effective for the delivery of oxygen, the

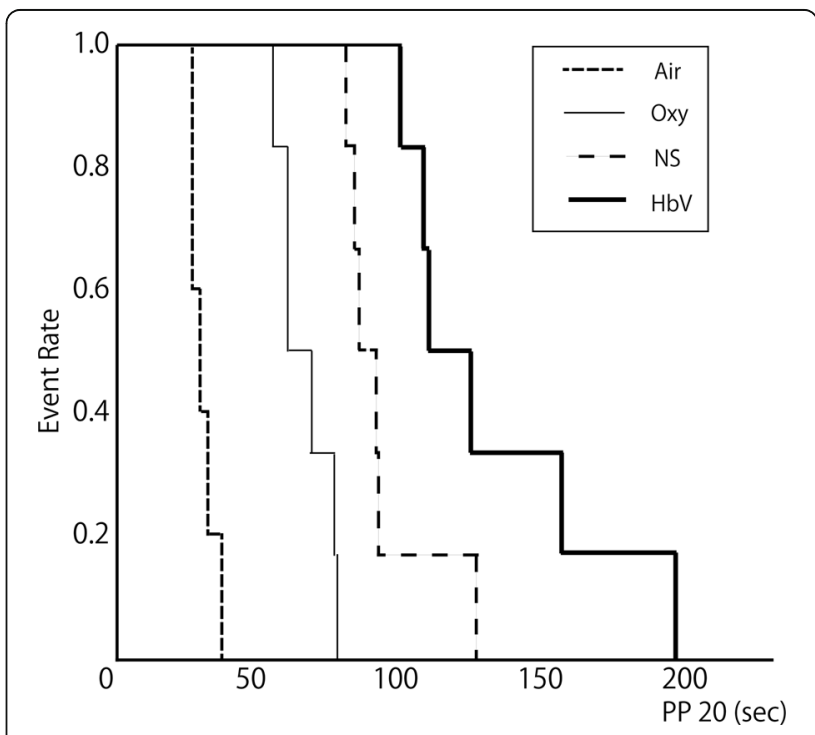

Fig. 3 A Kaplan-Meier curve for the apnea time to a pulse pressure less than $20 \mathrm{mmHg}$ for each group. There was a statistically significant difference between the groups assessed by a log-rank test (Air vs. HbV $P=0.004 ;$ Oxy vs. HbV, $P=0.003$; NS vs. HbV, $P=0.045$ ) 
$\mathrm{Hb}$-saline solution was found to be associated with high renal toxicity and vasopressive reactions; therefore, its use was discontinued. Subsequently, a large variety of modified HBOCs have been developed in an attempt to overcome these complications. These include cross-linked poly $\mathrm{Hb}$, conjugated $\mathrm{Hb}$, cross-linked tetrameric $\mathrm{Hb}$, recombinant human $\mathrm{Hb}$, and $\mathrm{HbV}[10,11,15-17]$. A number of these modified HBOCs have also been used to treat anaemic patients for whom a blood transfusion is not readily available [18]. However, other reports have indicated that these products are still associated with significant toxic properties that have been attributed to myocardial infarction, acute renal failure, a deleterious increase in arterial blood pressure, and death $[19,20]$. Such complications resulting from the use of HBOCs are thought to be mediated by the direct interaction between molecular $\mathrm{Hb}$ and the blood or endothelial cells; thus, preventing this direct contact via the encapsulation of $\mathrm{Hb}$ may lessen these complications. Previous studies have demonstrated that $\mathrm{HbV}$ does not exhibit renal toxicity or cause vasoconstriction [21]. Therefore, we can safely affirm that the haemodynamic difference observed in our study were not attributed to vasoconstriction.

Theoretically, an infusion of $6 \mathrm{~mL} \mathrm{HbV}$ will prolong the apnea time to circulatory collapse by $15 \mathrm{~s}$. To our surprise, the mean difference between the Oxy and the HbV groups was found to be $67.5 \mathrm{~s}$. This discrepancy may be explained by the results from the NS group. The NS group was included to assess the effect of the infusion volume since $\mathrm{HbV}$ does not have collioid osmotic pressure. We predicted that an infusion greater than $30 \%$ of the total circulating volume would lead to acute heart failure, shortening the $\mathrm{PP}_{20}$ in the NS group. However, the $\mathrm{PP}_{20}$ in the NS group was higher than that of the Oxy group. One reason for this might be the blood viscosity. Infusing normal saline causes haemodilution, resulting in a better cardiac contraction in the NS and HbV groups. Recently, it has been demonstrated that a saline infusion, while increasing the left ventricular end diastolic volume, also decreases the left ventricular end systolic volume resulting in increased cardiac contraction [22]. Although the administration of normal saline may have an impact on the time to circulatory collapse, any negative effects (e.g. high chloride acidosis or hypernatremia) should be noted. Another possible explanation involves a higher level of effective oxygen transport by $\mathrm{HbV}$ than RBCs to the myocardium, as it has a high oxygen consumption and steep oxygen tension gradient. Since $\mathrm{HbV}$ is smaller than RBCs, it is distributed closer to the endothelial cell layer during arteriolar blood flow, whereas RBCs flow closer to the axial line [23]. Biochemical data (e.g. base excess or lactate levels) may have been informative and supported our analyses; however, blood samples from the tail artery during circulatory collapse were not obtained.
We used the pulse pressure to define circulatory collapse in our study. The apnea time to reach a pulse pressure less than $20 \mathrm{mmHg}$ had the lowest coefficient of variation $(\mathrm{CV})$; a low $\mathrm{CV}$ value indicates high reproducibility. Although the pulse pressure at baseline in our results was close to $20 \mathrm{mmHg}$, all of the animals exhibited an increased pulse pressure and systolic blood pressure, reflecting a hyper haemodyanamic state following apnoea. Moreover, this phenomenon is consistantly observed in this model [9], indicating that the actual pulse pressure decreased from a higher value (i.e. $40 \mathrm{mmHg}$ ). Finally, we chose a pulse pressure less than $20 \mathrm{mmHg}$ as an outcome of this study based on our predefined protocol; however, there were also similar trends regarding the time to reach pulse pressures below 15 and $10 \mathrm{mmHg}$ between the groups.

Finally, the infusion of oxygenated hemoglobin (artificial or not) will increase the total amount of oxygen in the body. Therefore, our experimental results are natural in most part. However, $\mathrm{HbV}$ is an artificial $\mathrm{RBC}$, which can be stored at room temperature for more than 2 years. Moreover, the time required for the oxygenation of $\mathrm{HbV}$ in our experiment was within $5 \mathrm{~s}$. During critical hypoxic situations (e.g. CVCI), the time required for the preparation of the drug would be essential.

\section{Limitations}

Although all experiments were performed as thoroughly as possible, there are some limitations to this study. Firstly, we used the tail arteries to monitor any haemodynamic changes. As the tail artery is a small peripheral artery, the pulse pressure may be affected more by factors, such as blood pressure, blood volume and cardiac contractility. Thus, it may not be entirely reflective of the central haemodynamics, especially when the rats were in a state of near circulatory collapse. We have added one additional experiment to overcome this limitation, in which we monitored the pulse pressure in the tail artery and left common carotid artery consecutively. We found a strong relationship between the pulse pressures; however, they deviated greatly after the pulse pressure in the tail artery dropped lower than $25 \mathrm{mmHg}$. This may account for the finding that the $\mathrm{CV}$ was the lowest for $20 \mathrm{mmHg}$ but increased for the lower pulse pressures. In addition, the femoral artery or descending aorta may have more accurately assessed the central circulation in this study.

Secondly, our results may have been confounded by the significantly lower haemodynamic variables in the Air group compared to other groups at baseline. However, we do not believe this to be a serious limitation of our study as we successfully achieved the main endpoint by demonstrating that the $\mathrm{HbV}$ group exhibited a 
prolonged time to collapse compared to the Oxy and NS groups.

\section{Conclusion}

The infusion of $\mathrm{HbV}$ during apnoea in rats prolonged the time to circulatory collapse. The demonstration of $\mathrm{HbV}$ utility in a state of apnoea suggests that $\mathrm{HbV}$ may be efficacious as a bridging therapy in CVCI situations encountered clinically.

\section{Additional files}

Additional file 1: Figure S1. A Kaplan-Meier curve for the apena time to a pulse pressure less than $15 \mathrm{mmHg}$ for each group is shown. The $\mathrm{PP}_{15}$ times were $31.2 \pm 5.1 \mathrm{~s}, 78.8 \pm 21.0 \mathrm{~s}, 121 \pm 53.8 \mathrm{~s}$ and $155 \pm 44.4 \mathrm{~s}$ for the Air, Oxy, NS and HbV groups, respectively. Log-rank test revealed statistical difference between $\mathrm{HbV}$ and Air $(P=0.006), \mathrm{HbV}$ and Oxy $(P=0.003)$ but did not differ between HbV and NS $(P=0.04)$. (PNG $133 \mathrm{~kb}$ )

Additional file 2: Figure S2. A Kaplan-Meier curve for the apena time to a pulse pressure less than $10 \mathrm{mmHg}$ for each group is shown. The $\mathrm{PP}_{10}$ times were $58.8 \pm 35.8 \mathrm{~s}, 136 \pm 52.6 \mathrm{~s}, 155 \pm 68.8 \mathrm{~s}$ and $190 \pm 32.9 \mathrm{~s}$ for the Air, Oxy, NS and $\mathrm{HbV}$ groups, respectively. Log-rank test revealed statistical difference between $\mathrm{HbV}$ and Air $(P=0.006), \mathrm{HbV}$ and Oxy $(P=0.04)$ but did not differ between $\mathrm{HbV}$ and NS ( $P=0.82$ ). (PNG $116 \mathrm{~kb}$ )

\section{Abbreviations}

ANOVA: Analysis of variance; CV: Coefficients of variation; CVCl: Cannot ventilate, cannot intubate; Hb: Hemogloin; HBOC: Hb-based oxygen carrier; HbV: Hemoglobin vesicles; PLP: Pyridoxal 5'-phosphate; RBC: Red blood cell

\section{Acknowledgements}

The authors would like to thank Enago (www.enago.jp) for English language review.

\section{Funding}

This work was supported in part by Japanese Society for the promotion of Science grant. No funding was involved in in the design of the study and collection, analysis, and interpretation of data and in writing the manuscript.

\section{Availability of data and materials}

The datasets generated during the current study are available from the corresponding author on reasonable request.

\section{Authors' contributions}

YN: Study design, conducting experiment, data collection, data analysis and writing the first draft of the paper; SI: Data collection, data analysis and making advice for writing the first draft of the paper; HS: Preparation of Hemoglobin Vesicles, and making advice for writing the first draft of the paper; MK: Reviewing the first draft of the paper and rewriting. All authors read and approved the final manuscript.

\section{Competing interests}

The authors declare that they have no competing interests.

\section{Consent for publication}

Not applicable.

\section{Ethics approval}

The experiments were performed in 24 male rats (Sprague-Dawley, 300-330 g, 10 weeks old).

All experimental protocols were reviewed by the Committee on the Ethics of Animal Experiments at our University and were conducted in accordance with the Guidelines for Animal Experiments issued by the Nara Medical University and with law no. 105 (Act on Welfare and Management of Animals) issued by the Japanese government. The ethical guidelines conformed to the guiding principles issued by National Academy of Science.

\section{Publisher's Note}

Springer Nature remains neutral with regard to jurisdictional claims in published maps and institutional affiliations.

\section{Author details}

${ }^{1}$ Department of Anesthesiology, Nara Medical University, 840 Shijo-cho, Kashihara, Nara 634-8522, Japan. ²Department of Chemistry, Nara Medical University, 840 Shijo-cho, Kashihara, Nara, Japan.

Received: 23 September 2016 Accepted: 7 March 2017

Published online: 14 March 2017

\section{References}

1. Apfelbaum JL, Hagberg CA, Caplan RA, Blitt CD, Connis RT, Nickinovich DG, et al. Practice guidelines for management of the difficult airway: an updated report by the American Society of Anesthesiologists Task Force on Management of the Difficult Airway. Anesthesiology. 2013;118:251-70.

2. Curtis R, Lomax S, Patel B. Use of sugammadex in a 'can't intubate, can't ventilate' situation. Br J Anaesth. 2012;108:612-4.

3. Murphy C, Rooney SJ, Maharaj CH, Laffey JG, Harte BH. Comparison of three cuffed emergency percutaneous cricothyroidotomy devices to conventional surgical cricothyroidotomy in a porcine model. Br J Anaesth. 2011:106:57-64.

4. Sou K, Naito Y, Endo T, Takeoka S, Tsuchida E. Effective encapsulation of proteins into size-controlled phospholipid vesicles using freeze-thawing and extrusion. Biotechnol Prog. 2003;19:1547-52

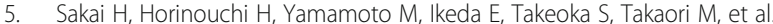
Acute 40 percent exchange-transfusion with hemoglobin-vesicles $(\mathrm{HbV})$ suspended in recombinant human serum albumin solution: degradation of $\mathrm{HbV}$ and erythropoiesis in a rat spleen for 2 weeks. Transfusion. 2006;46:339-47.

6. Seishi $Y$, Horinouchi $H$, Sakai H, Kobayashi K. Effect of the cellular-type artificial oxygen carrier hemoglobin vesicle as a resuscitative fluid for prehospital treatment: experiments in a rat uncontrolled hemorrhagic shock model. Shock. 2012;38:153-8.

7. Sakai H, Tomiyama Kl, Sou K, Takeoka S, Tsuchida E. Poly (ethylene glycol)conjugation and deoxygenation enable long-term preservation of hemoglobin-vesicles as oxygen carriers in a liquid state. Bioconjug Chem. 2000;11:425-32.

8. Fink EL, Alexander H, Marco CD, Dixon CE, Kochanek PM, Jenkins LW, et al. Experimental model of pediatric asphyxial cardiopulmonary arrest in rats. Pediatr Crit Care Med. 2004;5:139-44.

9. Katz L, Ebmeyer U, Safar P, Radovsky A, Neumar R. Outcome model of asphyxial cardiac arrest in rats. J Cereb Blood Flow Metab. 1995;15:1032-9.

10. Chang TM. Semipermeable microcapsules. Science. 1964;146:524-5.

11. Wong JT. Rightshifted dextran-hemoglobin as blood substitute. Biomater Artif Cells Artif Organs. 1988;16:237-45.

12. Sakai H, Hara H, Yuasa M, Tsai AG, Takeoka S, Tsuchida E, et al. Molecular dimensions of $\mathrm{Hb}$-based $\mathrm{O}_{2}$ carriers determine constriction of resistance arteries and hypertension. Am J Physiol Heart Circ Physiol. 2000;279:908-15.

13. Tajima Y. Jikken Doubutsugaku. Tokyo: Asakura Publishing; 1972.

14. Amberson WR, Jennings JJ, Rhode CM. Clinical experience with hemoglobin-saline solutions. J Appl Physiol. 1949;1:469-89.

15. Iwashita Y, Yabuki A, Yamaji K, Iwasaki K, Okami T, Hirata C, et al. A new resuscitation fluid "stabilized hemoglobin" preparation and characteristics. Biomater Artif Cells Artif Organs. 1988;16:271-80.

16. Bunn HF, Jandl JH. The renal handling of hemoglobin. Trans Assoc Am Physicians. 1968;81:147-52

17. Doherty DH, Doyle MP, Curry SR, Vali RJ, Fattor TJ, Olson JS, et al. Rate of reaction with nitric oxide determines the hypertensive effect of cell-free hemoglobin. Nat Biotechnol. 1998:16:672-6.

18. Mackenzie CF, Moon-Massat PF, Shander A, Javidroozi M, Greenburg AG When blood is not an option: factors affecting survival after the use of a hemoglobin-based oxygen carrier in 54 patients with life-threatening anemia. Anesth Analg. 2010;110:685-93.

19. Lamy ML, Daily EK, Brichant JF, Larbuisson RP, Demeyere RH, Vandermeersch EA, et al. Randomized trial of diaspirin cross-linked hemoglobin solution as an alternative to blood transfusion after cardiac surgery. The DCLHb Cardiac Surgery Trial Collaborative Group. Anesthesiology. 2000;92:646-56.

20. Natanson C, Kern SJ, Lurie P, Banks SM, Wolfe SM. Cell-free hemoglobinbased blood substitutes and risk of myocardial infarction and death: a meta-analysis. JAMA. 2008;299:2304-12. 
21. Sakai H, Hara H, Yuasa M, Tsai AG, Takeoka S, Tsuchida E, et al. Molecular dimensions of $\mathrm{Hb}$-based $\mathrm{O}_{2}$ carriers determine constriction of resistance arteries and hypertension. Am J Physiol Heart Circ Physiol. 2000;279:H908-15.

22. Robotham JL. Saline volume expansion and cardiovascular physiology: novel observations, old explanations, and new questions. Crit Care. 2004;8:315-8.

23. Sakai H, Tsai AG, Rohlfs RJ, Hara H, Takeoka S, Tsuchida E, et al.

Microvascular responses to hemodilution with $\mathrm{Hb}$ vesicles as red blood cell substitutes: influence of $\mathrm{O}_{2}$ affinity. Am J Physiol Heart Circ Physiol. 1999; 276:H553-62.

Submit your next manuscript to BioMed Central and we will help you at every step:

- We accept pre-submission inquiries

- Our selector tool helps you to find the most relevant journal

- We provide round the clock customer support

- Convenient online submission

- Thorough peer review

- Inclusion in PubMed and all major indexing services

- Maximum visibility for your research

Submit your manuscript at www.biomedcentral.com/submit 